\title{
Three Tubulin Genes of Trichoderma harzianum: Alpha, Beta and Gamma
}

\author{
Min $\mathbf{L i}^{1,2}$, Qian Yang ${ }^{2 *}$ and Jinzhu Song ${ }^{2}$ \\ ${ }^{1}$ Faculty of Chemistry Biology and Material Sciences; East China Institute of Technology; 344000; Fuzhou - China. \\ ${ }^{2}$ Department of Life Science and Engineering; Harbin Institute of Technology; 150001; Harbin - China.
}

\begin{abstract}
Three tubulin genes of Trichoderma harzianum were cloned followed genomic walking procedure. The tubulins showed high degree of amino acid homology with other fungal tubulins and were homologous with each other with 32 to 38\% amino acid identity. Three measures for the degree of codon usage bias indicated the presence of bias in all the sequences, suggesting high expression levels in all the genes. Protein structures were modeled to provide the basis for understanding the tubulin's properties and its interactions with microtubule-associated proteins. Potential motifs were also postulated.
\end{abstract}

Key words: Trichoderma harzianum, tubulin, codon usage bias, motif

\section{INTRODUCTION}

Seven members of tubulin family have been identified which include $\alpha-, \beta-, \gamma-, \delta-, \varepsilon_{-}, \zeta-$, and $\eta-$ tubulin. Genes for $\alpha-, \beta-$, and $\gamma$-tubulin are found in all eukaryotes, the last and new four tubulins, however, do not appear to have a ubiquitous distribution in eukaryotic organisms (Dutcher, 2001). The genes that encoded $\alpha-, \beta$-, and $\gamma$ tubulin were identified first in A. nidulans and functions were characterized subsequently. $\alpha$ - and $\beta$-tubulin are related proteins, which form a heterodimer that is the major building block of microtubules. $\gamma$-tubulin is found at microtubule organizing centers (MTOC) such as the spindle poles or the centrosome, suggesting that it is involved in the minus-end nucleation of microtubule assembly (Oakley, 2004). Besides progress on functions have been made, studies are being initiated to explore other important things, e.g., the mechanisms of regulation of microtubule dynamics in vivo, non-nucleation functions of $\gamma$ tubulin, and interactions of tubulins with kinesin, motor proteins and microtubule associated proteins. The antimicrotubule agents such as medically important cancer chemotherapy agents as well as agriculturally important fungicides, herbicides, and anthelmintic agents, are believed to target $\beta$-tubulin. Binding sites and precise mode of action of these agents remain to be determined.

Trichoderma harzianum (teleomorph: Hypocrea lixii) is active as a hyperparasite and has been extensively tested in field stuides. It has been shown to be an effective biocontrol agent, with good in vitro antagonistic abilities against a range of economically important aerial and soil-borne fungal plant pathogens (Gao et al., 2002). With the desire to implement the integrated control combining the biocontrol fungi with chemical fungicides, the obtaining of high resistant mutants with fitness and biocontrol advantages under field

\footnotetext{
*Author for correspondence: limin_hit@yahoo.com.cn
} 
conditions is a threshold for the adoption of these agents with traditional chemical fungicides.

The aim of this work was to clone $\alpha-, \beta_{1^{-}}$and $\gamma$ tubulin gene of $T$. harzianum and to model the dimensional structures as an initial step towards the characterization of cytoskeletal proteins and the realization of integrated control.

\section{MATERIALS AND METHODS}

The isolate $T$. harzianum T88 was obtained from the Northeast Forestry University and maintained on potato dextrose agar plates. The strain was cultured on potato dextrose medium at $25^{\circ} \mathrm{C}$, after which mycelia were harvested. Genomic DNA was isolated following the procedure described by Sambrook and Russell (2002).

$\alpha$-tubulin gene was amplified from the genomic DNA directly by a degenerate primer $\mathrm{P} \alpha 1$ and a specific primer $P \alpha 2$. P $\alpha 1$ was designed based on the conserved domains of $\alpha$-tubulin genes from other fungi. P $\alpha 2$ was designed based on an $\alpha$ tubulin gene EST sequence (GenBank accession no. DY762585) of T. harzianum T88 mycelium cDNA library constructed in our laboratory.

A fragment of $\beta_{1}$-tubulin gene was amplified by using a primer pair of $\mathrm{P} \beta_{1} 1$ and $\mathrm{P} \beta_{1} 2$. The two primers were designed based on the conserved domains of $\beta_{1}$-tubulin genes from other fungi. Inverse PCR (IPCR) method was applied to isolate the remaining $5^{\prime}$ - and $3^{\prime}$-coding regions and adjacent flanking sequences. An amount of $1.5 \mu \mathrm{g}$ genomic DNA was digested with restriction endonucleases

FbaI、NheI、SacI、NcoI、PstI、SacII、SpeI

AatII,SphI,ApaI and XbaI respectively. The digested DNA was precipitated with $5 \mu \mathrm{l} 3 \mathrm{M}$ $\mathrm{NaAc}(\mathrm{pH} 5.2)$ and $125 \mu \mathrm{l}$ absolute alcohol in $20^{\circ} \mathrm{C}$ for $2 \mathrm{~h}$, centrifuged $15 \mathrm{~min}$ at $12000 \mathrm{rpm}$, washed with $70 \%$ (v/v) ethanol, air-dried, and dissolved in $10 \mu \mathrm{l}$ distilled $\mathrm{H}_{2} \mathrm{O}$. Circularization by self-ligation was performed with $5 \mu$ l digested DNA (750 ng) in the presence of T4 DNA ligase (Takara, Japan), followed by precipitation with $\mathrm{NaAc}$ and ethanol, and the final extracts were dissolved in $10 \mu \mathrm{l}$ distilled $\mathrm{H}_{2} \mathrm{O}$. Subsequently, the IPCR reaction was performed with a primer pair of $\mathrm{P} \beta_{1} 3$ and $\mathrm{P} \beta_{1} 4$, using the resultant circularized DNA as template. The entire sequence of $\beta_{1^{-}}$ tubulin gene coding region plus flanking regions was obtained by splicing the fragments amplified by PCR.

A fragment of $\gamma$-tubulin gene was amplified first by using primers $\mathrm{P} \gamma 1$ and $\mathrm{P} \gamma 2$, and afterwards an IPCR was conducted to isolate the remaining regions with a primer pair of $\mathrm{P} \gamma 3$ and $\mathrm{P} \gamma 4$ according to the protocols used in $\beta_{1}$-tubulin gene amplification. Genomic DNA was digested with restriction

endonucleases

EcoRI、FbaI、HindIII、KpnI、PstI、SacI and SalI respectively.

Three-dimensional models of T. harzianum $\alpha-, \beta_{1^{-}}$ and $\gamma$-tubulin were built based on the crystal structures of Bos taurus $\alpha$-tubulin (1JFFA), B. taurus $\beta$-tubulin (1JFFB), and Homo sapiens $\gamma$ tubulin (1Z5VA) using the Swiss-Model Automated Comparative Protein Modeling Server in the first approach mode. The resulting structures were viewed with SwissPdb Viewer version 3.7, and files were exported to Photoshop 7.0. The theoretical analysis was carried out to find protein motifs whose consensus sequences were described using PredictProtein server. Emboss software was employed for codon usage analysis.

\section{RESULTS AND DISCUSSION}

A 1997 bp fragment was cloned by PCR amplification from the corresponding genomic DNA with primers $P \alpha 1$ and $P \alpha 2$. The product was examined, cloned, and sequenced on both the strands. Sequencing results of the amplicon confirmed that it contained 1868 bp ORF of $\alpha$ tubulin gene, with 534 bp $3^{\prime}$-nucleotide sequence corresponding to the previously isolated EST clone. Two fragments of 922 and $1030 \mathrm{bp}$ were obtained from genomic DNA with primers $\mathrm{P} \beta_{1} 1$, $\mathrm{P} \beta_{1} 2$ and $\mathrm{P} \gamma 1$, $\mathrm{P} \gamma 2$, respectively. Subsequently, primer pairs of $\mathrm{P} \beta_{1} 3, P \beta_{1} 4$ and $\mathrm{P} \gamma 3, \mathrm{P} \gamma 4$ were designed based on the resulting sequences and employed to IPCR to isolate the remaining $5^{\prime}$ - and $3^{\prime}$-coding regions and adjacent flanking sequences of $\beta_{1^{-}}$and $\gamma$-tubulin. The IPCR reactions succeeded in the amplification of $2094 \mathrm{bp}$ of a major product from ApaI-digested genomic DNA with $\mathrm{P} \beta_{1} 3$ and $\mathrm{P} \beta_{1} 4$, and 2510 bp from SalIdigested genomic DNA with $\mathrm{P} \gamma 3$ and $\mathrm{P} \gamma 4$. Meanwhile, reactions with other endonucleasestreated DNA produced no major product. A 2734 bp fragment was obtained by splicing the cloned 922 and 2094 bp sequences, which included 
1764 bp ORF of $\beta_{1}$-tubulin gene, 819 bp of upstream region and $151 \mathrm{bp}$ corresponding to the downstream region. Simultaneously, a 3335 bp fragment was obtained by splicing the cloned 1030 and 2510 bp sequences, which was identified including 1941 bp ORF of $\gamma$-tubulin gene. The list of products information and nucleotide sequences of primers used are shown in Table 1. The nucleotide sequences of $\alpha$-, $\beta_{1^{-}}$and $\gamma$-tubulin have been submitted to GenBank under accession no. EF063142, EF027166 and EF027168 respectively. $\alpha$ - and $\beta_{1}$-tubulin are related proteins with 449 and 445 amino acid (a.a.) and about the same mass of 50.1 and $49.5 \mathrm{kD}$. The two proteins are homologous but not identical with $38 \%$ a.a. identity. In consequence, they were proposed to constitute two highly conserved families of proteins within the tubulin superfamily (Oakley, 2000). $\gamma$-tubulin gene encodes a protein of 462 a.a. with a theoretical molecular mass of $51.7 \mathrm{kDa}$, exhibiting 32 and $34 \%$ a.a. identity with $\alpha$ - and $\beta_{1^{-}}$ tubulin, respectively (Fig 1 ). Since $\alpha$ - and $\beta_{1-}$ tubulin share more similarity with each other than with $\gamma$-tubulin, it is likely that the original tubulin split into $\gamma$-tubulin and an ancestor of $\alpha$ - and $\beta$ tubulin, which, in turn, split again to form the $\alpha$ tubulin and $\beta$-tubulin families (Oakley, 2000). Simultaneously, $\beta_{1}$-tubulin displayed $88 \%$ a.a. identity with another beta tubulin of T. harzianum characterized as reported previously ( $\mathrm{Li}$ and Yang, 2007). In addition, $\alpha-, \beta$-, and $\gamma$-tubulin are also recognized as highly conserved proteins among species. T. harzianum $\alpha$ - and $\beta_{1}$-tubulin amino acid sequences were found with similarities of 89 and $86 \%$ with the corresponding sequences of Neurospora crassa, while $\gamma$-tubulin appeared slightly more divergent with a similarity of $80 \%$ with $N$. crassa $\gamma$-tubulin. $\alpha$ - and $\gamma$-tubulin gene have six introns and $\beta_{1}$-tubulin gene has four, all of which contain consensus splicing junctions adhering to the GT-AG rule. The intron positions were inferred from comparison with other genes and the consensus sequences but were not verified by the cDNA sequence.

Codon usage bias is known to be highly variable among the genes for a given species (Comeron and
Aguadé, 1998). It may also correlate with gene expression levels in many organisms (Ghosh et al., 2000). For T. harzianum $\alpha-, \beta_{1^{-}}$, and $\gamma$-tubulin, whether the NC index, ranging between 29.3 and 52.6 , or the CAI, with values $>0.72$, being the two measures for the degree of codon usage bias, indicated the presence of bias in any of the sequences. The frequency of purines in the third position in synonymous codons (GC3s) was calculated and resulted in values indicative of bias in any of the sequences, suggesting high expression levels in all the genes. $\gamma$-tubulin gene was predicted with slightly lower expression levels than $\alpha$ - and $\beta_{1}$-tubulin gene. Experiments using in vitro translated monomeric $\gamma$-tubulin showed that a single $\gamma$-tubulin subunit was sufficient to nucleate microtubules (Leguy et al., 2000). Although the analysis of codon usage data based on the sequence information of individual genes has been shown to be a suitable indirect indicator of gene expression levels in many organisms, the real levels need eventually to be confirmed by direct assessment methods.

As a key feature of tubulins, GTP-binding sites are conserved in $T$. harzianum $\alpha$-, $\beta_{1^{-}}$, and $\gamma$-tubulin at residues from 140 or 142 . Its consensus pattern was almost identical to the GTP-binding site of bacterial protein ftsZ whose role in prokaryotes was probably similar to that of tubulins. Similarly, $\mathrm{N}$-glycosylation site and glycosaminoglycan attachment site were found in all the subunits that also had protein kinase $\mathrm{C}$ phosphorylation site, casein kinase II phosphorylation site and $\mathrm{N}$ myristoylation site. However, except for $\beta_{1}$ tubulin, $\alpha$ - and $\gamma$-tubulin each conserved one amidation site. In addition, tyrosine kinase phosphorylation site and cell attachment sequence, i.e. the RDG tripeptide sequence were identified in $\alpha$-tubulin, and two cAMP and cGMP phosphorylation sites (KRIS) were present in $\gamma$ tubulin. The typical consensus pattern of $\beta$ subunits, MREI, was found as the first tetrapeptide in $\beta_{1}$-tubulin aminoterminal, which has been thought sufficient to confer tubulin-dependent autoregulation on thymidine kinase mRNA (Bachurski et al., 1994). 


\begin{abstract}
$\alpha$-tubulin 1 M-REVISMNVGQAGCQIANSCWELYCLEHGIQPDGYLTEERKAQDPDQGF STFFSETGQG $\beta_{1}$-tubulin 1 M-REIVHLQTGQCGNQVGSAFWQTISGEHGLDASGVYGGTSDQQ--LERLNVYF NEASGN $\gamma$-tubulin $\quad 1$ MPREIITIQAGQCGNSIGSOEWQQLCQEHGISQDGNLEDFATEG--GDRKDVFYYQSDDT

$\alpha$-tubulin 60 KYVPRAIYCDLEPNVVDEVRTGPYRNLFHPEMMITGKE--DASNNYARGHYTVGKELIEG $\beta_{1}$-tubulin 58 KYVPRAVLVDLEPGTMDAVRSGPFGQLFRPDNFVFGQS--GAGNNWAKGHYTEGAELVDQ $\gamma$-tubulin 59 RYIPRAILIDLEPRVLNSIITGPYRN I YNPENEYVGKNGMGAANNWGD G-YQSGEAVYED

$\alpha$-tubulin 118 VLDKIRRVADNCVGLQGFLVFHSFGGGTGSGFGALLMERLSVDYGKKSKLEFCVYP-APQ $\beta_{1}$-tubulin 116 VLDVVRREAENCECLQGEQITHSIGGGTGSGMGILIISKIREEFPDRMMATF SVVP-SPK $\gamma$-tubulin 118 VMEMIDREADGSDSLEGFMMLSIAGGTGSGLGSFLLERLNDREPKKI IQTYSVEPNITN

$\alpha$-tubulin 177 TATSVVEPYNS ILITHTTLEHSDCSFMVDNEAIYDICRRNLGLERPNYENLNRLIAAVVVS $\beta_{1}$-tubulin 175 VSDIVVEP YNATLSMHQLVENSDKTECIDNEALYD ICMRTLKLSNP SY GDLNHLVSAVMS $\gamma$-tubulin 178 APDVVVHPYNS I LSMRRLTQNADSVVVIDNGALSHIAADRLHVQEPSFQQTNQLVATVMS

$\alpha$-tubulin 237 SITASLRFDGSLNVDLNEFQTNLVPYPRIHFPLVAYAPVIS---AAKAAHEANSVQEMTM $\beta_{1}$-tubulin 235 GVSTSLRFPGQLNSDLRKLAVNMVP ERLHFFMVGFAPLTS---PGAHSFRAVISVPEITQ $\gamma$-tubulin 238 A ASTTTLRYPGYMHNDLVSILASLIPTPRCHFLMTAYTPFTGDQVEQAKTVRKTIVLDVMR

a-tubulin 294 SCFEPNNQMVKCDP-RNGKYMATCLLYRGDVVPNDAHNAVATLKTKRTIQFVDWCPTGFK $\beta_{1}$-tubulin 292 QMLDPKNMMAASDE-RNGRYLTCSTIFRGKVAMKEVEDQMRSIQNKNSTYFVEWIPNNIQ $\gamma$-tubulin 298 RLLQPKNRMVSIVPGKKSCYISI LNVIQGEVDBTDVHKSLLRIRERKLATEIPWGPASIQ

$\alpha$-tubulin 353 LGICYQAPENVPNGDLAKVNRAVCMLSNITAIAEAŴSSLSLKFDLMHSKRAFVHWYVGEG $\beta_{1}$-tubulin 351 TALCS IPPK-------GLKISSTFVGNSTAIQEIFRRVGEF SAMFRRKAF LHWYTSEG $\gamma$-tubulin 358 VALTKRSPYMP-----MSHRVS GLMLANHISIATLEKRILKQYD GMRKRNAF IEGYKKTA

$\alpha$-tubulin $413---M E E G E F S E A R E D I A A L E R D Y E E V A A D S L D N-E E M E A E Y$

$\beta_{1}$-tubulin 403 ---MDEMEFTEAESNMNDLVSEYQQYQDATADDGEEYEEEVPMEEE---$\gamma$-tubulin 413 PFSENLDEFDEARQVVSDLIQEYEAAEDADYLNPDSGEKATSAETDRRMA
\end{abstract}

Figure 1 - Multiple sequence alignment of T. harzianum $\alpha-, \beta_{1^{-}}$, and $\gamma$-tubulin.
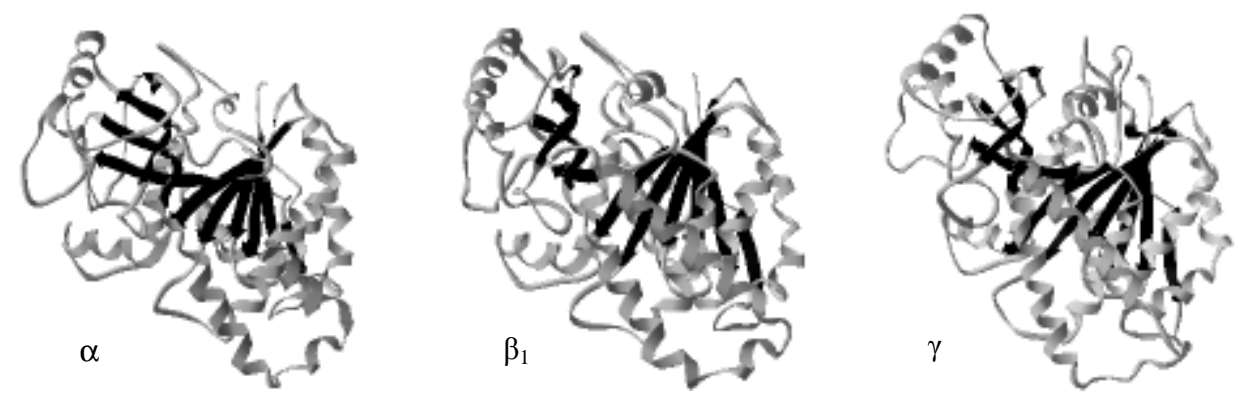

Figure 2 - Ribbon models of T. harzianum $\alpha$-, $\beta_{1^{-}}$, and $\gamma$-tubulin. 
Table 1 - Products information and nucleotide sequences of primers used in amplification

\begin{tabular}{|c|c|c|c|}
\hline Primer & Nucleotide sequence & Position & Product length $(\mathrm{bp})$ \\
\hline $\mathrm{P} \alpha 1$ & 5'-ATGMGHGARGTCATYAGYWTSAA-3' & 1 & \multirow{2}{*}{1997} \\
\hline$P \propto 2$ & 5'-AACTGAGGCTTGCGACCTA-3' & 1979 & \\
\hline $\mathrm{P} \beta_{1} 1$ & 5'-TCGTYCGTCGCGAGGCTGAGAA-3' & 782 & \multirow{2}{*}{922} \\
\hline $\mathrm{P} \beta_{1} 2$ & 5'-TGGTAYTGYTGGTAYTCGGARACRAG-3' & 1678 & \\
\hline$P \beta_{1} 3$ & 5'-TGGTACACTAGCGAGGGTATGG-3' & 1615 & \multirow{2}{*}{2094} \\
\hline $\mathrm{P} \beta_{1} 4$ & 5'-TAAGGCTCGACAACGGTATCC-3' & 954 & \\
\hline $\mathrm{P} \gamma 1$ & 5'-TTTGCGACMGARGGCGG-3' & 344 & \multirow{2}{*}{1030} \\
\hline P $\gamma_{2}$ & 5'-ACCATSCGRTTCTTVGGCTG-3' & 1354 & \\
\hline $\mathrm{P} \gamma 3$ & 5'-ACCGGTGACCAAGTTGAGCAG-3' & 1282 & \multirow{2}{*}{2510} \\
\hline P $\gamma 4$ & 5'-AGGCAGCAGGGCAAACATACTC-3' & 441 & \\
\hline
\end{tabular}

The analysis of tertiary structures of $T$. harzianum $\alpha-, \beta_{1^{-}}$, and $\gamma$-tubulin showed that there was a high degree of resemblance among these proteins (Fig 2). Each monomer was formed by two interacting beta sheets surrounded by alpha helices. Divergently, $\alpha$ - and $\beta_{1}$-tubulin monomers were identical with $10 \beta$-strands, while $\gamma$-tubulin had one more $\beta$-strand than $\alpha$ - and $\beta_{1}$-tubulin. The structures of $\alpha$ - and $\beta_{1}$-tubulin are very compact, but can be divided into three functional domains. The amino-terminal domain forms a classical Rossmann fold (Rossmann et al., 1974), at the base of which sits the nucleotide. The intermediate domain is formed by a mixture of four $\beta$-sheets and $\alpha$-helices. The carboxy-terminal domain is all alpha helical and overlaps the two previous domains, making the 'crest' of the protofilament on the outside surface of the microtubule where microtubule-associated proteins and motor proteins bind (Downing and Nogales, 1998). Furthermore, the carboxy-terminal domain may be a target for posttranslational modifications (MacRae, 1997). The analysis of the amino acid sequences of $\alpha$ - and $\beta_{1}$-tubulin shows that their primary structure is highly conserved in the amino-terminal and intermediate sequence, but is highly divergent in the carboxyl-terminal sequences. Mutations at codons 6, 50, 134, 165, $167,198,200,240,241$, and 257 in $\beta$-tubulin gene have been shown in previous studies to cause benzimidazole resistance in more than 16 fungi. Although the amino acids which altered benzimidazole resistance varied in positions in different fungi, and the same residue with different substitutions might correlate with different resistance levels (Ma and Michailides, 2005), the relative importance of the residues in these motifs in the $T$. harzianum $\beta_{1}$-tubulin need eventually to be confirmed by site-directed mutagenesis.

The predicted secondary and tertiary structures of T. harzianum tubulins might provide a basis for understanding the tubulin's properties and interactions with antimicrotubule agents, but the limitations of computational prediction methods also would need to be resolved further.

\section{REFERENCES}

Bachurski, C. J.; Theodorakis, N. G..; Coulson, R. M. R. and Cleveland, D. W. (1994), An amino-terminal tetrapeptide specifies cotranslational degradation of $\beta$-tubulin but not $\alpha$-tubulin mRNAs. Mol. Cell. Biol., 14, 4076-4086.

Comeron, J. M. and Aguadé, M. (1998), An evaluation of measures of synonymous codon usage bias. $\mathrm{J} \mathrm{Mol}$. Evol., 47, 268-274.

Downing, K. H. and Nogales, E. (1998), Tubulin and microtubule structure. Curr Opin. Cell. Biol., 10, 1622.

Dutcher, S. K. (2001), The tubulin fraternity: alpha to eta. Curr Opin. Cell. Biol., 13, 49-54.

Gao, K. X.; Liu, X. G.; Liu, Y. H.; Zhu, T. B. and Wang, S. L. (2002), Potential of Trichoderma harzianum and T. atroviride to control Botryosphaeria berengeriana f. sp. piricola, the cause of apple ring rot. J Phytopathol., 150, 271-276.

Ghosh, T. C.; Gupta, S. K. and Majumdar, S. (2000), Studies on codon usage in Entamoeba histolytica. Int J Parasitol., 30, 715-722.

Leguy, R.; Melki, R.; Pantaloni, D. and Carlier, M. F. (2000), Monomeric $\gamma$-tubulin nucleates microtubules. J Biol. Chem., 275, 21975-21980.

Li, M. and Yang, Q. (2007), Isolation and characterization of $\beta$-tubulin gene from Trichoderma harzianum. Biochem. Genet., 45, 529-534. 
Ma, Z. H. and Michailides, T. J. (2005), Advances in understanding molecular mechanisms of fungicide resistance and molecular detection of resistant genotypes in phytopathogenic fungi. Crop. Prot., 24, 853-863.

MacRae, T. H. (1997), Tubulin post-translational modifications enzymes and their mechanisms of action. Eur J. Biochem., 244, 265-278.

Oakley, B. R. (2000), An abundance of tubulins. Trends. Cell. Biol., 10, 537-542.

Oakley, B. R. (2004), Tubulins in Aspergillus nidulans. Fungal. Genet. Biol., 41, 420-427.
Rossmann, M. G.; Moras, D. and Olsen, K. W. (1974), Chemical and biological evolution of a nucleotidebinding protein. Nature., 250, 194-199.

Sambrook, J. and Russell, D. W. (2002), Molecular cloning: a laboratory manual. Cold Spring Harbor Laboratory Press, Cold Spring Harbor, pp. 96-102.

Received: September 11, 2007; Revised: October 15, 2008; Accepted: October 14, 2009. 